\title{
REFLEXÕES SOBRE POLÍTICA INDUSTRIAL E DESENVOLVIMENTO NA CHINA
}

\author{
Joyce Helena Ferreira da Silva ${ }^{1}$
}

\begin{abstract}
Resumo: Este artigo tem como objeto traçar um panorama do processo de industrialização chinês - tendo como elemento central as políticas industriais. A partir disto, busca-se identificar a atuação do Estado na condução do desenvolvimento econômico, em conformidade com aparatos teóricos que dão relevo ao desenvolvimento industrial como motor dinâmico da economia. Em termos epistemológicos, a consideração do desenvolvimento econômico e da industrialização, como condição sine qua non para o alcance do bem-estar social, caracteriza este artigo como uma leitura inserida no paradigma moderno. Apesar disto, ao longo do trabalho, existe um esforço em apresentar uma China que possui particularidades e cujo legado (rejeitado por esta mesma lógica eurocêntrica) deve ser reafirmado, a fim de que seja possível recontar a História através da inclusão de atores centrais que foram apagados pela ocidentalização dos fatos.
\end{abstract}

Palavras-chave: China; Política Industrial; Desenvolvimento Econômico.

Abstract: This article is an overview of the process of Chinese industrialization. We seek, therefore, to identify the performance of the State in the conduct of economic development, in accordance with theoretical frameworks that give emphasis to industrial development as a dynamic motor of the economy. In epistemological terms, the consideration of economic development and industrialization as a sine qua non condition for achieving social welfare, characterizes this article as an approach embedded in the modern paradigm. Despite this, throughout the work, there is an effort to present the Chinese particularities and their legacy (rejected by this same Eurocentric logic) that must be reaffirmed, so that it is possible to retell history through the inclusion of central actors who have been erased by the Westernization of the facts.

Key Words: China; Industrial Policy; Economic Development.

\section{Introdução}

O homem de bem conhece a retidão, o homem de baixa condição não conhece senão o lucro. $\mathrm{O}$ homem de bem é imparcial e visa o universal; o homem de baixa condição, ignorando o universal, fecha-se no sectário.

Confúcio $^{2}$

O trecho supracitado parece bastante elucidativo no que diz respeito à filosofia chinesa mais reconhecida, o confucionismo, e que influenciou historicamente a formação desta sociedade. Neste fragmento, é possível identificar a ênfase no bem comum, em detrimento da lógica individualista e do ganho privado sobre o coletivo, elementos evidenciados no nexo ocidental padrão, especialmente a partir da década de 1980.

\footnotetext{
${ }^{1}$ Doutora em Ciência Política, Pesquisadora associada do Instituto de Estudos da Ásia da Universidade Federal de Pernambuco. Atualmente, é Professora do curso de Relações Internacionais da Faculdade Damas. Contato: Rua Ministro João Alberto, Caxangá, Recife-PE, Brasil. E-mail: joyce.hfs87@gmail.com.

${ }^{2}$ CHENG, A. História do Pensamento Chinês. Rio de Janeiro: Vozes, 2008, p. 70.
} 
Compreender a China é um exercício que excede a pura análise de fatos e dados políticos e econômicos, exige, para além disto, a captura de relevantes nuances, em boa medida, mais subjetivas. Esta subjetividade está exposta em uma racionalização diferenciada da organização social, pavimentada por uma filosofia que garante a formação de um sistema moral diferenciado.

A ascensão chinesa é um dos principais acontecimentos do século XXI, entretanto, a magnitude desta economia não é um fenômeno inusitado na História. A avaliação de políticas industriais ou mesmo, de forma mais ampla, a dinâmica contemporânea de desenvolvimento chinês (pós-Reformas de 1978) não podem ser fragmentados de processos anteriores. Neste sentido, é necessário reconhecer a primazia da China anterior à Revolução Industrial, fenômeno que coloca a Europa no centro da ordem econômica mundial. Acompanhando a leitura feita por Gunder Frank, ${ }^{3}$ identificase que a economia-mundo é formada por vários centros, todos integrados dentro da ordem global. Segundo ele, durante muito tempo o centro econômico predominante sobre todo o conjunto foi o chinês e não o europeu.

Desta forma, a amplitude da economia chinesa superava a de todos os Estados da Europa, sendo que, até o advento da Revolução Industrial, a China predominava no cenário internacional. Conforme destacado:

Durante as dinastias Ming e Qing, a China experimentou aumentos maciços de produção, consumo e população, que foram brevemente interrompidos durante a transição Ming/Qing em meados do século XVII. [...] A China era inigualável na produção de cerâmicas de porcelana e tinha poucos rivais em seda, que era o principal produto de exportação. ${ }^{4}$

Até o século $\mathrm{XV}$, o país asiático possuía a maior renda per capita do mundo e a primazia no que diz respeito aos processos de inovação tecnológica. Neste sentido, "embora a renda per capita do continente europeu tenha recuperado a chinesa por volta de 1500, a China continua a deter o maior produto nacional até o começo do século XIX”. Para se ter a dimensão do tamanho daquela economia, em 1750, o país asiático era responsável por $32,8 \%$ da produção manufatureira mundial. A partir de 1500, acelera-se o processo de decadência da economia chinesa, em especial por sua fragilidade externa - um descolamento entre avanço civilizacional (progresso

\footnotetext{
${ }^{3}$ FRANK, André G. ReOrient: global economy in the Asian age. Los Angeles: University of California Press, 1998.

${ }^{4}$ Idem, p. 111.
} 
econômico e cultural) e força político-militar -, movimento que rebaixaria o país a uma condição de subdesenvolvimento. ${ }^{5}$

Em linhas gerais, pode-se argumentar que o êxito chinês, em especial durante a dinastia Song (960-1279), esteve associado a um arcabouço político fundamentado na ideologia neoconfuciana, a qual enfatiza a lealdade à autoridade no contexto de uma ordem social hierárquica. Neste sentido, é de relevo ressaltar a predominância de um crescente ativo cultural (educação, filosofia, literatura e artes), que se reflete em altíssimo nível cultural da elite política chinesa.

Apesar da riqueza histórica do período dinástico chinês, não cabe, neste breve artigo, trabalhar de forma pormenorizada os termos deste momento específico. Por ora, alguns aspectos estão colocados apenas para lançar luz sobre o fato de que a dimensão atual da economia chinesa e sua crescente influência no sistema internacional não é um movimento pontual e abrupto, deslocado de outros processos históricos. Um dos elementos centrais da dinâmica de desenvolvimento da China contemporânea é seu movimento de industrialização. Isto indica a relevância de um momento histórico precedente às reformas de Deng Xiaoping em 1978: a China de Mao Zedong.

Este artigo tem como objetivo uma breve análise dos principais movimentos de industrialização na China apontando, especialmente, para a questão das políticas industriais. Desta forma, busca-se identificar a atuação do Estado na condução de um processo de desenvolvimento via industrialização, em conformidade com aparatos teóricos que dão relevo ao desenvolvimento industrial como motor dinâmico da economia.

Em outras palavras, a China é um parâmetro em termos de economia em desenvolvimento e, ao mesmo tempo, é um agente ativo no processo de reprimarização da pauta de exportações brasileiras em curso. Nestes termos, é de relevo compreender a China por uma $(i)$ perspectiva de possibilidades de emulação de algumas políticas, transplantando-as com a devida adaptação à realidade concreta brasileira, e para (ii) tentar fazer frente aos impactos que o crescimento desta economia provocou na dinâmica brasileira, no caso específico, como lidar com o avançado processo de especialização regressiva da pauta exportadora.

\footnotetext{
${ }^{5}$ LYRIO, M. C. A ascensão da China como potência: fundamentos políticos internos. Brasília: FUNAG, 2010, p. 17 e 18.
} 


\section{Indústria e socialismo no pré-1978: a adoção do modelo soviético de industrialização rápida}

Aspectos preliminares: A China dialética e um socialismo controverso

Em primeira instância, antes de se conhecer os pormenores da industrialização chinesa e seus aspectos econômicos mais gerais, cabem alguns comentários preliminares. A consolidação do socialismo na China é um tema controverso quando se confronta teoria e práxis política. Isto porque, do ponto de vista da construção teórica marxiana, a China não seguiria as etapas necessárias para a construção do modo de produção socialista. Isto quando se observa a teoria marxiana em termos rígidos.

A vanguarda revolucionária dos trabalhadores operários não foi uma realidade na revolução chinesa de 1949, como também não havia sido na Revolução Russa de 1917. Sendo um país predominantemente agrário, foram os camponeses que tomaram o protagonismo do processo e aqui estaria o principal ponto de divergência com a ortodoxia marxista. Em um cenário como este, a alocação dos recursos e a própria dinâmica da acumulação socialista adquirem características particulares.

Alinhando-se com a perspectiva de Pomar, ${ }^{6}$ entende-se que não se pode confundir a "análise lógico-dialética das contradições internas e do desenvolvimento do capital" com a "análise histórico-concreta". Para a primeira, "o desenvolvimento do capital é estudado idealmente, sem a interferência dos fatores condicionantes"; para a segunda categoria, em que se encaixa o caso chinês e qualquer outro episódio empírico, tem relevância a consideração do que "Lênin chamava de análise concreta da situação concreta".

Nesta mesma direção, Harvey argumenta que deve ser feita uma interpretação da obra marxiana em uma direção que calibre argumentações históricas e lógicas, sendo necessário avaliar quando uma se sobrepõe à outra. Segundo ele, "o verdadeiro poder do argumento [em Marx] só se torna claro quando, tendo retornado ao reino da experiência, vemos que possuímos um arcabouço inteiramente novo de conhecimento para compreender e interpretar essa experiência". ${ }^{7}$ Neste sentido, a própria leitura marxiana da realidade deve ser feita como um processo de confrontação entre teoria e realidade concreta.

\footnotetext{
${ }^{6}$ POMAR, W. O enigma chinês. $2^{\text {a }}$ Edição. São Paulo: Fundação Perseu Abramo, 2015, p. 16.

${ }^{7}$ HARVEY, D. Para entender o capital: livro I. São Paulo: Boitempo, 2013, p. 18.
} 
Mais problemática e enigmática, entretanto, é a avaliação do que seria o socialismo na China contemporânea. Uma nova discussão se forma em torno do que seria a construção de um 'socialismo de mercado'. O papel do consumo na economia e a criação de novos produtos como uma necessidade social, por exemplo, parecem aspectos próprios da dinâmica de acumulação capitalista; entretanto, este processo ocorre em concomitância com uma robusta ampliação do poder de consumo da classe trabalhadora, reduzindo desigualdades, e com uma presença marcante do Estado via planejamento e propriedade de empresas em setores-chave. ${ }^{8}$

Em uma perspectiva comparativa dentro do próprio arcabouço socialista, seria possível relacionar as políticas de Deng Xiaoping, a partir de 1978, com as medidas tomadas por Lênin quando estabelecida a Nova Política Econômica (NEP) em 1921? Kenny ${ }^{9}$ argumenta que sim, tendo em vista que a NEP instituiu na URSS uma espécie de capitalismo de Estado: (i) estabelecimento de joint-ventures e concessões a empresas estrangeiras; (ii) cooperativas baseadas em mecanismos de mercado; (iii) formação de quadros técnicos formados com métodos de gestão e organização capitalistas; (iv) arrendamento de empresas estatais e de recursos naturais para empresas privadas nacionais e estrangeiras.

Ao mesmo tempo, a China se insere no capitalismo mundial de modo muito mais integrado do que no caso da NEP na URSS, dependendo, segundo o autor, de uma ordem política e militar dirigida pelo imperialismo norte-americano. Provavelmente, isto fará desta versão chinesa da NEP, se assim for possível caracterizar a economia socialista de mercado, um caminho sem volta, onde as estruturas capitalistas tenderão a se agudizar.

Neste sentido, a China permanece contraditória, provavelmente, muito mais no pós-Reforma do que na era maoísta. Isto porque, ao mesmo tempo em que lança mão de mecanismos de mercado e promove uma inserção internacional que abarca não só o comércio exterior (mas também uma forte financeirização, assuntos de ordem geopolítica, etc.), a China mantém intactos elementos como planejamento estatal de sua economia, estabelece junto a outros países em desenvolvimento uma frente de contraposição às instituições do capitalismo central, apenas para citar alguns aspectos.

\footnotetext{
${ }^{8}$ POMAR, W. O enigma chinês. Op. cit. KENNY, T. Lições da NEP soviética para Economia Socialista de Mercado da China Popular. 2008. Disponível em: <http://www.histsocialismo.com/docs/NEPsovietica-ESMChina.pdf>. Acessado em: 27 Mar. 2017.

${ }^{9}$ Ibidem.
} 
Junte-se a isto o debatido discurso da ascensão pacífica, e o rechaço a pretensões imperialistas, ao mesmo tempo em que é protagonista de uma espécie de neocolonialismo brando na África e na América Latina, criando dinâmicas que aprisionam aqueles países em suas condições históricas de subdesenvolvimento. Em termos de funcionamento de unidade de contrários, a China é um país por excelência dialético.

\section{A China não nasce em 1978: a industrialização Era Mao}

A China não é resultado unilateral do processo iniciado em 1978, por Deng Xiaoping. Como descrito, o país asiático foi, até a Revolução Industrial, a maior economia do mundo, estando na vanguarda econômica e tecnológica. Não cabe, neste espaço restrito, uma revisão exaustiva deste encadeamento histórico. Entretanto, o referente episódio merece, ao menos, ser citado como nota convidativa a um combate ao eurocentrismo, que impõe a consolidação do capitalismo ou a modernidade europeia como marco central da História, infligindo à China um papel menor, periférico. Quer dizer, a China não se agiganta por se render ao mercado; mais do que isto, a China já era proeminente antes mesmo do mercado.

Para os termos deste artigo, é relevante iniciar tratando do processo de industrialização colocado em marcha a partir do estabelecimento da República Popular da China. A consolidação política do novo regime tem seu momento crucial entre a tomada do poder pelos comunistas na Revolução de 1949 e o Grande Salto Adiante, em 1953. É nesta fase que se identifica a transição socialista cujos pilares econômicos são a (i) coletivização da agricultura e a (ii) industrialização em moldes soviéticos.

Este modelo tem como características o monopólio da indústria pelo Estado, a mobilização de recursos para um processo rápido via indústria pesada (big push development strategy), em detrimento da indústria de bens de consumo ${ }^{10}$, e a adoção de

\footnotetext{
${ }^{10}$ Os bens de consumo classificados como "bens racionados", como comida, grãos, açúcar, eram distribuídos pelos consumidores por meio de um sistema de racionalização, de forma controlada; aqueles bens considerados "não-racionados" eram vendidos em lojas operacionalizadas pelo planejamento central GONÇALVES, A. "China's swing from a planned soviet-type economy to an ingenious socialist market economy: an account of 50 years.” In: Working Papers Series, Social Sciences Research Network, 2006. Disponível em: <http://ssrn.com/abstract=949371>ou<http://dx.doi.org/10.2139/ssrn.949371>. Acessado em: 17 março 2017.
} 
planejamento central através da formulação de Planos Quinquenais. ${ }^{11}$ A formatação da economia chinesa, a partir da República Popular da China é subdividida em um gigantesco setor estatal que controla grandes empresas, a indústria e as minas; fazendas privadas, que serão, posteriormente, coletivizadas e pequenas e médias empresas privadas.

Neste momento, a China passa a emular o modelo soviético de industrialização, especialmente durante a primeira década da República Popular da China, nos anos 1950. Isto significa que a estratégia soviética de desenvolvimento Big Push e a forma de controle da economia, centralizada e baseada no planejamento, são copiadas no país asiático; da mesma forma, tanto a tecnologia industrial quanto o aparato organizacional são transplantados da URSS para a China. ${ }^{12}$

Para se ter um parâmetro do tamanho do esforço de industrialização na China, a participação do investimento estatal no PIB, desde a década de 1950 até os dias atuais, nos países pobres ronda, em média, os 20\%; na China, nesta condição, em 1954, o investimento estava acima dos $26 \%$. Deste total, $80 \%$ foi destinado à indústria, em especial, à indústria pesada. Na China pós reformas, o investimento chegou a um patamar de $40 \%$ do PIB, enquanto que este permanece um dos maiores gargalos da economia brasileira, por exemplo. Mesmo no período recente de grande crescimento, no superciclo das commodities, a participação do investimento no PIB não chega nem mesmo aos $20 \%$ acima mencionados.

Como se observa no gráfico que segue, a partir de 1954, ocorre um crescimento robusto do investimento, trajetória que é interrompida a partir da crise provocada pelas falhas do Grande Salto Adiante (1958-1961). Entretanto, ainda na década de 1960, ocorre uma recuperação, cujo pico se dá em 1967, quando o investimento chega a ultrapassar os $30 \%$. Após o processo de reforma e abertura, esta variável se mantém sempre acima do patamar de 30\%, sendo um dos componentes explicativos do persistente dinamismo do crescimento chinês.

\footnotetext{
${ }^{11}$ FAIRBANK, K. J.; GOLDMAN, M. China: a new history. London: The Belknap Press of Harvard University Press, 2006.

${ }^{12}$ NAUGHTON, Barry. The Chinese Economy: transitions and growth. Cambridge, MA: MIT Press, 2007.
} 


\section{Gráfico 1. Participação do investimento no PIB chinês (\%)}

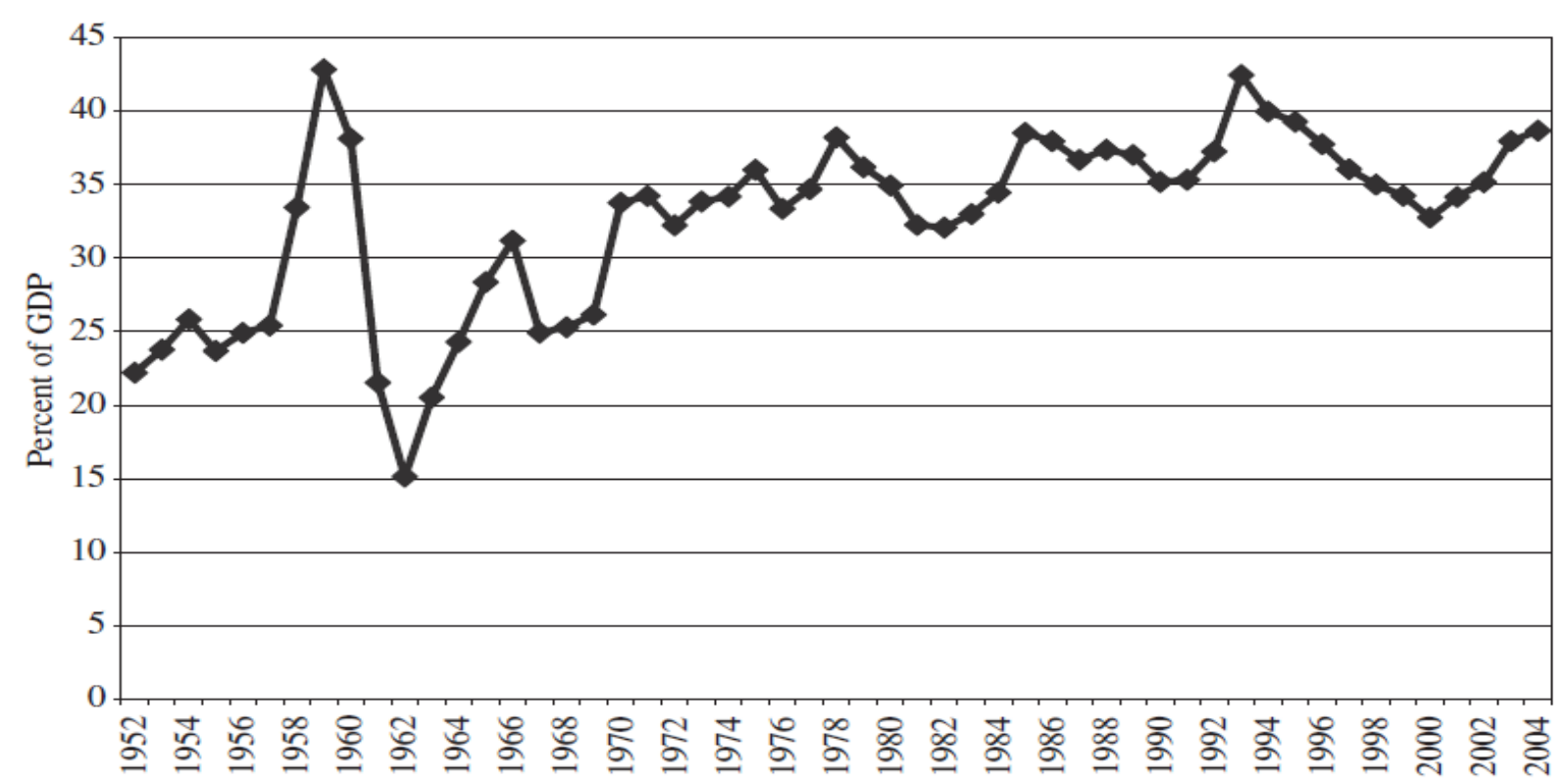

Fonte: NAUGHTON, Barry. The Chinese Economy. Op. cit., p. 57.

O traço mais relevante do viés soviético na industrialização chinesa é a centralidade da indústria de aço, tendo a agricultura o papel de intermediário, de setor gerador de excedente. Isto se dava a partir necessidade de suprir não apenas as condições de subsistência do trabalhador urbano, somado a isto, o setor agrícola seria o vetor maximizador do crescimento industrial via comércio exterior. Com a exportação de produtos agrícolas, seria possível a geração de divisas para aquisição de máquinas, equipamentos e tecnologia para o processo de industrialização. ${ }^{13}$

A tabela que segue mostra que o processo de industrialização chinês não deve ser completamente atribuído ao período pós-Reformas, em 1978, tendo em vista que já estava em curso um movimento ampliação significativo da participação do setor, tanto no PIB quanto no emprego total. Como se pode observar, em 1952, a participação da indústria no PIB chinês era de $21 \%$ e correspondia a apenas $7 \%$ do emprego. Em 1978, quando se iniciam as modernizações, o setor secundário já era responsável por $48 \%$ do PIB da China. No que diz respeito ao emprego, entretanto, ainda prevalecia o trabalho no setor agrícola, com participação de $71 \%$.

\footnotetext{
${ }^{13}$ KUEH, Y. Y. "Mao and agriculture in China's industrialization: three antitheses in a 50 -year perspective. "In: The China Quartely. 2006. Disponível em: <https://www.cambridge.org/core/services/aop-cambridgecore/content/view/S03057410 06000336>. Acessado em: 15 mar. 2017.
} 


\section{Tabela 2. Participação no PIB e no Emprego Total por setores em 1952 e 1978 (\%)}

\begin{tabular}{ccccc} 
& $\mathbf{1 9 5 2}$ & $\mathbf{1 9 5 2}$ & $\mathbf{1 9 7 8}$ & $\mathbf{1 9 7 8}$ \\
\cline { 2 - 5 } & PIB & $\begin{array}{c}\text { Emprego } \\
\text { Total }\end{array}$ & PIB & $\begin{array}{c}\text { Emprego } \\
\text { Total }\end{array}$ \\
\hline Agricultura & 51 & 84 & 28 & 71 \\
\hline Indústria & 21 & 7 & 48 & 17 \\
\hline Serviços & 28 & 9 & 24 & 12 \\
\hline Total & 100 & 100 & 100 & 100 \\
\hline
\end{tabular}

Fonte: KUEH, Y. Y. "Mao and agriculture in China’s industrialization”. Op. cit., p. 707. Elaboração própria.

Três reformas parecem intimamente interligadas, seriam elas: (ii) a formação da indústria pesada; (iii) o aumento da área irrigada e, finalmente; (iv) a criação de uma indústria de insumos agrícolas. Esta simbiose entre os setores agrícola e industrial passava pela realização de uma importante reforma - que, no caso do Brasil, por exemplo, é, ainda hoje, fonte de problemas estruturais graves. Trata-se da Reforma Agrária, que possibilitou a democratização da terra na China, bem como o aumento da produtividade e da renda do trabalhador rural.

Aproximadamente 47 milhões de hectares teriam sido divididos entre 300 milhões de camponeses pobres, o que marcaria a seguinte modificação na estrutura rural chinesa: 40 milhões de camponeses com propriedade superior à média tiveram suas terras reduzidas; 70 milhões de camponeses mantiveram suas terras e 300 milhões de camponeses conquistaram sua propriedade. ${ }^{14} \mathrm{Com}$ o processo de coletivização do campo, aos poucos, as pequenas propriedades familiares foram sendo substituídas pelas fazendas coletivas. Enquanto aproximadamente $2 \%$ das famílias produziam em cooperativas em 1954; em 1955, este total passou para 14\%, sendo ampliado para a quase totalidade já em 1956, quando 98\% das famílias camponesas da China produziam em fazendas coletivas. ${ }^{15}$

Segundo Gonçalves (2006), portanto, a Lei da Reforma Agrária teria três objetivos: ( $i$ ) o fim da propriedade feudal e a neutralização de uma aristocracia rural tradicional; (ii) a redistribuição de terra para camponeses pobres, os quais eram o núcleo principal da população rural chinesa; (iii) a proteção dos interesses dos pequenos e

\footnotetext{
${ }^{14}$ DIEGUES, A. C.; MILARÉ, L. F. L. "Contribuições da Era Mao Tse-Tung para a industrialização chinesa.” In: Revista Economia Contemporânea, Rio de Janeiro, v. 16, n. 2, mai-ago/2012, p. 364.

${ }^{15}$ NAUGHTON, Barry. The Chinese Economy. Op. cit.
} 
médios proprietários de terra e seu distanciamento da influência dos grandes proprietários.

Neste ponto, cabe identificar uma convergência entre o modelo chinês do período em discussão e a referência teórica de Oskar Lange. ${ }^{16}$ Lange destaca a relevância do planejamento no socialismo e revela que, neste modo de produção, a composição das classes no poder e forma de apropriação do excedente são um ponto de distinção do modelo capitalista. A China de Mao é um bom exemplo empírico destes aspectos. Ao enfraquecer uma tradicional fração de classe (a dos grandes proprietários rurais) e romper com antigas estruturas de pensamento, o governo modifica a correlação de força entre as classes sociais. A forma de apropriação do excedente agrícola para fomento da indústria é outro aspecto que corrobora a teoria de Lange.

O subdesenvolvimento teria, em suas bases, do ponto de vista material, a deficiência em termos de bens de capital e a concentração de terras, ou seja, a questão agrária. Ao atacar estas duas deficiências, erguendo a indústria pesada e promovendo a reforma agrária, pode-se identificar, já na China maoista, o primeiro e mais importante esforço no sentido de romper com o subdesenvolvimento.

A primeira prática de planejamento socialista na China foi colocada em execução no período 1953-1957 (Primeiro Plano Quinquenal) e tinha como objetivo a construção de 694 unidades fabris, das quais 156 seriam construídas com ajuda do governo soviético. Em termos de crescimento econômico, o Primeiro Plano Quinquenal produziu um crescimento anual médio de $8,9 \% .^{17}$

Durante este período, foram realizados importantes investimentos em infraestrutura e na indústria, sendo que, já em 1957, a China possuía indústria de produção de aço, aviões, automóveis, equipamentos de geração de eletricidade e máquinas pesadas. ${ }^{18}$ Como se pode observar na tabela abaixo, mais do que alcançadas, as metas foram, em larga medida, ultrapassadas:

\footnotetext{
${ }^{16}$ LANGE, O. Ensaios sobre planificação econômica. São Paulo: Nova Cultural, 1986.

${ }^{17}$ FAIRBANK, K. J.; GOLDMAN, M. China. Op. cit. GONÇALVES, A. "China's swing from a planned soviet-type economy to an ingenious socialist market economy: an account of 50 years. ” Op. cit.

${ }^{18}$ POMAR, W. O enigma chinês. Op. cit.
} 


\section{Tabela 3. Valor Bruto da Produção no Primeiro Plano Quinquenal} (em milhões de yuans/1952)

\begin{tabular}{|c|c|c|c|c|}
\hline $\begin{array}{lll}\text { Valor } & \text { Bruto } & \text { da } \\
\text { Produção } & & \\
\end{array}$ & $\begin{array}{l}1952 \\
\text { (realizado) }\end{array}$ & $\begin{array}{l}1957 \\
\text { (planejado) }\end{array}$ & $\begin{array}{l}1957 \\
\text { (realizado) }\end{array}$ & $\begin{array}{l}\text { Realizado } \\
1957 / 1952\end{array}$ \\
\hline Industrial & 27.010 & 53.560 & 65.020 & $141 \%$ \\
\hline $\begin{array}{l}\text { Energia elétrica } \\
\text { (kwh bilhões) }\end{array}$ & 7 & 16 & 19 & $166 \%$ \\
\hline Máquinas (em unidades) & 13.734 & 12.720 & 28.000 & $104 \%$ \\
\hline $\begin{array}{l}\text { Locomotivas } \\
\text { (em unidades) }\end{array}$ & 20 & 200 & 167 & $735 \%$ \\
\hline $\begin{array}{ll}\text { Vagões } & \text { ferroviários } \\
\text { (unidades) } & \\
\end{array}$ & 5.792 & 8.500 & 7.300 & $26 \%$ \\
\hline $\begin{array}{l}\text { Navios mercantes } \\
\text { (mil toneladas dwt) }\end{array}$ & 22 & 179 & 54 & $151 \%$ \\
\hline
\end{tabular}

Fonte: Elaboração própria com base em dados selecionados de Spence (1990 apud DIEGUES, A. C.; MILARÉ, L. F. L. “Contribuições da Era Mao Tse-Tung para a industrialização chinesa.” Op. cit.).

A cooperação junto à União Soviética foi estabelecida logo em 1949, através do Friendship Alliance and Mutual Assistance Treaty. O Primeiro Plano Quinquenal seguiu o modelo soviético e o governo chinês obteve suporte considerável do então aliado. Entretanto, o estabelecimento do Grande Salto Adiante (1958-1961) representou um dos principais elementos de ruptura entre os dois países, o que se deu concretamente em 1960, quando a URSS cancelou sua ajuda técnica, financeira e de assistência à China.

O Grande Salto Adiante foi recebido com descrédito pelo governo soviético, especialmente por práticas do tipo backyard steel, onde, a fim de alcançar a meta de produzir em quatro meses a mesma quantidade de aço atingida nos oito meses anteriores, foi construído um esforço que envolvia, inclusive, o derretimento de panelas nos quintais das casas. ${ }^{19}$ Neste sentido, a falta de realismo na concepção das metas e o descolamento entre o planejamento e o que se poderia alcançar diante da realidade econômica do país produziram críticas e descontentamento dos antigos aliados.

Outro elemento do afastamento do modelo de corte soviético foi a compreensão, por parte do governo chinês, de que não seria mais viável o estabelecimento de um planejamento estritamente centralizado. Isto significou uma descentralização que conferiu maior poder às províncias, como uma forma de favorecimento das capacidades

\footnotetext{
${ }^{19}$ PALESE, A. "The Great Leap Forward (1958-1961): Historical events and causes of one of the biggest tragedies in People's Republic of China’s history.” In: Språk-ochlitteraturcentrum, 2009.
} 
e responsabilidades de administradores locais, técnicos e dos próprios trabalhadores. ${ }^{20}$ Em termos práticos, as empresas submetidas à autoridade central foram reduzidas de um total de 9.300 para apenas 1.200 e os itens econômicos controlados pelo governo central diminuíram de 532 para 132, o que, do ponto de vista do aumento da produtividade, foi positivo. $^{21}$

Define-se, portanto, que, entre o período 1949-1978, a China esteve sob um arranjo que combinava centralização política e desconcentração econômica, ainda que apenas parcial. Ainda assim, diante de acusações de revisionismo de ambos os lados e do crescimento de divergências geopolíticas, em 1964, a relação diplomática sinosoviética é oficialmente rompida.

Ainda que tenha produzido um importante impacto na indústria, pelo lado da produção agrícola, o Grande Salto Adiante apresentou deficiências que geraram problemas sociais graves. Em uma "economia planificada são as restrições pelo lado da oferta agregada que condicionam o ritmo de crescimento do país, na medida em que o governo dispõe de meios para mobilizar toda a capacidade produtiva e força de trabalho disponíveis"; diante disto, o governo chinês fez uma escolha deliberada pela indústria em detrimento do setor agrícola, tendo, ainda, proporcionado um deslocamento de trabalhadores do campo para atividades urbanas que reduziu a oferta de alimentos de forma considerável. ${ }^{22}$

Além de falhas na alocação de recursos, na época da execução do Grande Salto Adiante, a China ainda passou por problemas de ordem natural que diminuíram a produção de alimentos. Desta forma, o abastecimento das áreas urbanas, que alimentavam os trabalhadores da indústria, permaneceu relativamente regular, enquanto as áreas rurais foram negligenciadas.

No início dos anos 1970, a China passa por conflitos internos e externos. No âmbito do Partido Comunista, crescem as dissensões entre seus membros; no que diz respeito às questões externas, a inclusão da URSS entre seus adversários regionais e a aproximação com os Estados Unidos, em 1972, provocam uma reconfiguração das relações exteriores do país. Em 1973, três anos antes da morte de Mao, Deng Xiaoping

\footnotetext{
${ }^{20}$ GONÇALVES, A. "China's swing from a planned soviet-type economy to an ingenious socialist market economy: an account of 50 years." Op. cit.

${ }^{21}$ POMAR, W. A Revolução Chinesa. São Paulo: Editora Unesp, 2003.

${ }^{22}$ CARVAlHO, M. H. A evolução econômica e política da China no período maoista (1949-1978). Disponível em: <http://www.niepmarx.com.br/MM2015/anais2015/mc84/Tc841.pdf>. Acesso em: 22 mar. 2017, p. 7.
} 
volta ao poder ${ }^{23}$ como vice-premier, sendo o principal defensor e articulador da desregulamentação da economia.

Já em 1975 são anunciadas as chamadas 'Quatro Modernizações', referentes aos setores da agricultura, indústria, tecnologia e forças armadas, sendo após a morte de Mao Tse Tung, no ano seguinte, 1976, que estas propostas passam a ter centralidade no governo chinês enquanto política econômica. ${ }^{24}$

\section{Socialismo com características chinesas: aspectos do processo de Reforma e Abertura}

A industrialização da era maoista obteve um salto qualitativo relevante para a distribuição de riqueza regional na China. Antes do estabelecimento da República Popular, a indústria chinesa já estava majoritariamente concentrada na zona costeira do país, pela facilidade no acesso aos portos: em 1933-1934, nas províncias de Guangdong, Jiangsu, Shandong, Hebei e Liaoning ficavam localizadas quase metade da indústria mineradora e praticamente todas as empresas de algodão e seda, enquanto Xangai, sozinha, possuía metade das indústrias (ainda precárias) do país. No fim da década de 1940, Xangai era responsável por $61 \%$ do emprego industrial e tinha $60 \%$ das fábricas mais modernas. ${ }^{25}$

Entretanto, as próprias políticas do Primeiro Plano Quinquenal já apresentavam uma preocupação com a questão regional:

Por exemplo, dos 700 maiores projetos industriais do primeiro plano quinquenal, mais de 2/3 dos projetos industriais foram localizados no interior do país, o que correspondeu a $69 \%$ dos investimentos estatais. Essa estratégia favoreceu o deslocamento de atividades industriais para o interior e estimulou o surgimento de centros urbanos nas regiões centrais. ${ }^{26}$

Desta forma, antes de aprofundar a discussão sobre as transformações da China atual, é necessário salientar que o período que antecede as reformas foi fundamental para o estabelecimento do país que se tornou a segunda economia do mundo. Como argumenta Ping:

\footnotetext{
${ }^{23}$ Deng Xiaoping havia sido excluído dos fóruns decisórios do PCC durante a Revolução Cultural (19661976), justamente por apoiar medidas liberalizantes.

${ }^{24}$ RUIZ, R. M. Polarizações e desigualdades: desenvolvimento regional na China. Texto para Discussão. Belo Horizonte: UFMG/Cedeplar, n. 299, 2006.

${ }^{25}$ PAINE, S. "Spatial Aspects of Chinese Development: issues, outcomes and policies 1949-1979." In: The Journal of Development Studies, 1983. RUIZ, R. M. Polarizações e desigualdades. Op. cit.

${ }^{26}$ Idem, p. 13, grifo nosso.
} 


\begin{abstract}
A formação da propriedade pública e da economia planejada resultou na necessidade de acelerar a industrialização, ou seja, naquela época, em condições de escassez de capital, a China aumentou o investimento de capital, dependendo tanto da depressão do consumo interno quanto da acumulação. Nos 25 anos, entre 1953 a 1978, a China manteve uma taxa de crescimento econômico relativamente alta, e quase montou um sistema industrial autárquico, que estava estreitamente e inseparavelmente relacionado a uma alta taxa de acumulação. Além disso, a propriedade pública e o sistema de planejamento econômico têm outra função: garantir a segurança social a todas as pessoas na China, assegurar a estabilidade social durante um período de alta acumulação e deficiência de bens e materiais, embora esse tipo de segurança social esteja em um contexto de níveis de renda baixos. ${ }^{27}$
\end{abstract}

É importante reconhecer estas bases, pois, é a partir dela que se processa a inserção dos mecanismos de mercado na China pós-1978. A ascensão de Deng Xiaoping inaugura importantes modificações na estrutura econômica chinesa. Uma das principais marcas do processo de reforma e abertura é o gradualismo com que a transição ocorre. No que diz respeito às empresas estatais, não foram diretamente privatizadas e o governo optou por introduzir gradativamente os instrumentos de mercado, reduzindo aos poucos as restrições ao capital privado em vários setores, inclusive na agricultura, onde se executou uma descoletivização e o estabelecimento de mercados locais. ${ }^{28}$

Em sua fase inicial, portanto, a reforma estabelecia o fim da coletivização na área rural, a abertura para o investimento estrangeiro e para o capital privado, ainda que grande parte das indústrias permanecessem sob controle estatal. A partir disto, são colocadas as bases de um modelo de industrialização que privilegia a promoção de exportações, tendo como fundamentos a criação de um ambiente institucional favorável e a desvalorização da moeda. ${ }^{29}$

As primeiras etapas da reforma tiveram como alvo principal as áreas da agricultura e o comércio exterior, especialmente no período 1978-1984. A nova configuração política chinesa previa uma combinação entre socialismo e mercado, onde o planejamento macroeconômico e macrossocial seriam compactuados com mecanismos de mercado como base para o cálculo econômico, sendo que o Estado

\footnotetext{
${ }^{27}$ PING, L. "China". In: LASTRES, H. M. M.; SCERRI, M. (orgs.). The role of the State. Nova Deli: Routledge, 2014, p. 194.

${ }^{28}$ PINGYAO, L. "China's economic growth: new trends and implications." In: China \& World Economy. N. 1, 2003. RUIZ, R. M. Polarizações e desigualdades. Op. cit.

${ }^{29}$ Ibidem.
} 
cumpriria o papel de reparador dos desvios de mercado e de orientador, a fim de que fosse orientado para as estratégias gerais de desenvolvimento. ${ }^{30}$ Desta forma:

Ainda subsistem monopólios estatais em áreas sensíveis do abastecimento e ainda existem preços administrados para uma série de produtos básicos, como alimentos populares, transportes, etc. No entanto, a tendência é que, à medida que a escassez seja superada e os rendimentos elevados, os monopólios restantes sejam quebrados e o mercado vá paulatinamente determinando todos os preços conforme a relação entre oferta e procura. ${ }^{31}$

Esta reorganização político-econômica faz com que a China obtenha altas taxas de crescimento. Entre as décadas de 1980 e 1990, o país obteve uma taxa média de crescimento de 9,5\%, embora se deva reconhecer que, entre 1965 e 1980, a economia já crescia a uma taxa média de 6,5\%, o que não é um dado trivial. Mais uma vez, o setor agrícola exerceu um papel fundamental para o fortalecimento da indústria chinesa, na era Mao para ampliação de setores de base e, no pós-1978, para a consolidação do setor de bens de consumo. A partir das reformas, a mecanização da agricultura e a criação de um complexo agroindustrial permitiram a expansão da indústria leve de consumo. ${ }^{32}$

Como fora brevemente discutido, no início deste artigo, a China apresenta contradições aparentes que, na verdade, se apresentam de forma bastante funcional. Um destes elementos é a prática simultânea de abertura e protecionismo. Enquanto na América Latina estes dois polos se apresentaram de maneira relativamente distinta (ora se optou pelo protecionismo, ora se optou pela abertura irrestrita), no caso do país asiático, houve uma convergência entre estes dois vetores, isto é, praticou-se, a partir de 1978, tanto a abertura quanto a proteção de empresas locais.

As Zonas Econômicas Especiais (ZEEs) são os locais onde esta aparente contradição se coloca efetivamente. As ZEEs funcionam como plataformas de exportação, tendo em vista que o comércio exterior, bem como os investimentos, são as variáveis centrais no crescimento econômico chinês. O componente de abertura das ZEEs consiste em serem regiões captadoras de investimentos e de instalação de empresas estrangeiras; entretanto, estas áreas possuem elementos de protecionismo ao não adotarem abertura irrestrita, tendo em vista que os investidores estrangeiros estariam condicionados a promover uma associação com empresas nacionais,

\footnotetext{
${ }^{30}$ POMAR, W. A Revolução Chinesa. Op. cit.

${ }^{31}$ Idem, p. 111.

32 MEDEIROS, C. A. Notas sobre o desenvolvimento econômico recente na China. Instituto de Estudo Avançados USP, São Paulo: 1998.
} 
transferindo tecnologia. Este é um dos traços significativamente divergentes entre o ingresso de capital estrangeiro na China e no Brasil, onde, neste último, em geral, as empresas multinacionais não estiveram submetidas a compromissos de parcerias com empresas locais.

Um movimento de industrialização acelerado tem como efeito imediato um aumento da população urbana e a necessidade de organização deste processo. No caso chinês, "o Estado mantém sua política geral de impedir o inchamento desordenado das cidades", "entre 1979 e 2000, os investimentos em moradia representaram cerca de $23 \%$ dos investimentos em ativos fixos sociais e a superfície das habitações foi ampliada em mais de dezoito bilhões de metros quadrados". Na extensão urbana, " $a$ área habitacional per capita passa de 3,8m², em 1978, para 9,3m², em 1998, enquanto nas zonas rurais passou de $8,1 \mathrm{~m}^{2}$ para $23,7 \mathrm{~m}^{2}{ }^{2}{ }^{33}$

Segundo Medeiros ${ }^{34}$, parte significativa dos investimentos públicos na China é direcionada à construção civil. Até meados dos anos 2000, a taxa de urbanização cresceu $38 \%$ ao ano, o que implica uma demanda gigantesca por moradia, tendo sido este um dos setores que mais impulsionaram o mercado doméstico chinês desde o processo e aceleração da industrialização.

Ainda que a presença do Estado permanecesse ampla, mesmo após a reforma, é relevante destacar uma alteração na sua forma de atuação. Especialmente no período 1949-1976, o gerenciamento estatal se dava majoritariamente via planejamento central. Com o processo de abertura e a inserção de mecanismos de mercado, houve uma relativa substituição do planejamento central e uma opção pela regulação política indireta. Daquele primeiro modelo restariam ainda duas bases: (i) alocação de crédito via bancos estatais e (ii) forte presença de empresas estatais em setores estratégicos, as quais seguem o planejamento do governo. ${ }^{35}$ Desta forma, o Estado chinês não deixa de executar o planejamento, em vez disso, ele passa a articular planejamento com políticas indiretas e permite a inserção gradativa de instrumentos típicos de economias de mercado.

\footnotetext{
33 POMAR, W. A Revolução Chinesa. Op. cit., p 125.

34 MEDEIROS, C. A. "A China como um duplo polo na Economia Mundial e a recentralização asiática." In: Revista de Economia Política, São Paulo, v. 26, n. 3, p. 381-400, julho/setembro. 2006.

${ }^{35}$ Ibidem.
} 


\section{A Política industrial na China}

A política industrial chinesa é um mecanismo usado pelo governo que não se pode enquadrar através de planos específicos, bem definidos através de nomes, prazos e relacionados com governos. Trata-se de uma política industrial difusa, sempre presente, mas, sem um projeto bem delineado. Exemplo disto é que, mesmo depois de práticas concretas de valorização do setor industrial e de um nítido reconhecimento da indústria como centro dinâmico do desenvolvimento chinês, o termo política industrial só aparece no sétimo Plano Quinquenal (1986-1990).

Existe na literatura uma vastidão de interpretações que procura indicar se a China seguiu um modelo de industrialização ao estilo asiático (como Japão, Coreia do Sul, etc.) ou se tem em suas bases uma dinâmica própria, independente. É ponto de descanso, entretanto, a compreensão de que a China se beneficiou de uma formatação geopolítica parcialmente virtuosa no continente asiático, de divisão regional do trabalho. Coloca-se este elemento virtuoso como 'parcial' porque, em termos estritamente políticos, a China sempre esteve em um ambiente regional bastante hostil, com rivalidades históricas com Índia, Japão, URSS, etc.

Entretanto, do ponto de vista econômico, no continente asiático, a partir do Japão e, posteriormente, das demais experiências de desenvolvimento, ocorreu difusão e transferência tecnológica, estabelecimento de fluxos comerciais e financeiros intensos e uma reestruturação industrial japonesa, que abriu espaço para a formação de uma cadeia regional de produção.

Em termos internos, a China norteou seu desenvolvimento industrial, no período pós-reforma, nos seguintes pilares: (i) mudança estrutural; (ii) propriedade estatal e controle das atividades econômicas; (iii) capacidade estatal e (iv) evolução dos regimes de demanda ${ }^{36}$. O quadro abaixo explica cada uma destas bases:

\section{Quadro 1. Pilares do desenvolvimento econômico chinês no período} Pós-Reforma

\begin{tabular}{|c|l|}
\hline $\begin{array}{c}\text { Mudança } \\
\text { estrutural }\end{array}$ & $\begin{array}{l}\text { Transição de uma industrialização trabalho-intensivo na primeira } \\
\text { fase (1978-1992) para um modelo capital-intensivo (a partir de } \\
\text { 1992). }\end{array}$ \\
\hline
\end{tabular}

\footnotetext{
${ }^{36}$ LO, D.; WU, M. The State and industrial policy in Chinese economic development. 2014. Disponível em: <http://www.ilo.org/global/publications/books/WCMS_315676/lang--en/index.htm>. Acessado em: 27 Abril 2017.
} 


\begin{tabular}{|c|l|}
$\begin{array}{c}\text { Propriedade } \\
\text { estatal e controle } \\
\text { das atividades } \\
\text { econômicas }\end{array}$ & $\begin{array}{l}\text { Predominância da propriedade estatal na primeira etapa da } \\
\text { reforma e participação reduzida, porém significativa, na segunda } \\
\text { etapa (pós-1992). Controle estatal da alocação de recursos } \\
\text { financeiros e participação majoritária de bancos estatais. }\end{array}$ \\
\hline $\begin{array}{c}\text { Capacidade } \\
\text { estatal }\end{array}$ & $\begin{array}{l}\text { Descentralização do poder como característica da transformação } \\
\text { econômica, sendo governos locais importantes players } \\
\text { econômicos. }\end{array}$ \\
\hline $\begin{array}{c}\text { Evolução dos } \\
\text { regimes de } \\
\text { demanda }\end{array}$ & $\begin{array}{l}\text { O desenvolvimento chinês foi conduzido, no primeiro momento, } \\
\text { pela maior participação do consumo no gasto agregado e, a partir } \\
\text { da década de 1990, pelo investimento e, em menor extensão, } \\
\text { pelas exportações. Neste movimento, a queda da participação do } \\
\text { consumo final no gasto agregado foi de mais de 10\% entre o final } \\
\text { da década de 1980 e meados dos anos 1990. }\end{array}$ \\
\hline
\end{tabular}

Fonte: Adaptado de LO, D.; WU, M. The State and industrial policy in Chinese economic development. Op. cit. Elaboração própria.

Esta "mudança estrutural", que marca a transição da indústria trabalho-intensivo para capital-intensivo foi facilitada pelo esforço de industrialização anterior às reformas, durante as décadas de 1950 e 1970 . Em outros termos, este arranjo trabalho-intensivo e a ampliação do consumo no gasto agregado tiveram suas bases na estrutura montada na promoção da indústria pesada. No que diz respeito à 'propriedade estatal', as empresas estatais e aos bancos públicos chineses:

[...] eram responsáveis por sustentar o padrão existente de distribuição de renda igualitária. Proporcionaram segurança no emprego e serviços sociais para virtualmente toda a população urbana, fomentando assim a "revolução do consumo", que foi essencial para a industrialização naquele período.

Como o termo 'política industrial' passou a ser utilizado a partir de 1986, é apenas em 1989 que começam a aparecer projetos específicos, diferentes dos Planos Quinquenais, os chamados Programas Nacionais de Política Industrial. Entretanto, conforme afirmam Heilmann e Shih, ${ }^{38}$ a amplitude quantitativa e setorial destes programas estive bastante limitada, principalmente entre 1989 e 2004, quando estavam restritos a projetos de reestruturação setoriais individuais. Estes mesmos autores oferecem os números de projetos efetivos:

\footnotetext{
${ }^{37}$ Idem, p. 314.

${ }^{38}$ HEILMANN, S.; SHIH, L. "The rise of industrial policy in China, 1978-2012." In: HarvardYenching Institute. Working Paper Series, 2013.
} 


\section{Gráfico 2. Programas Nacionais de Política Industrial na China}

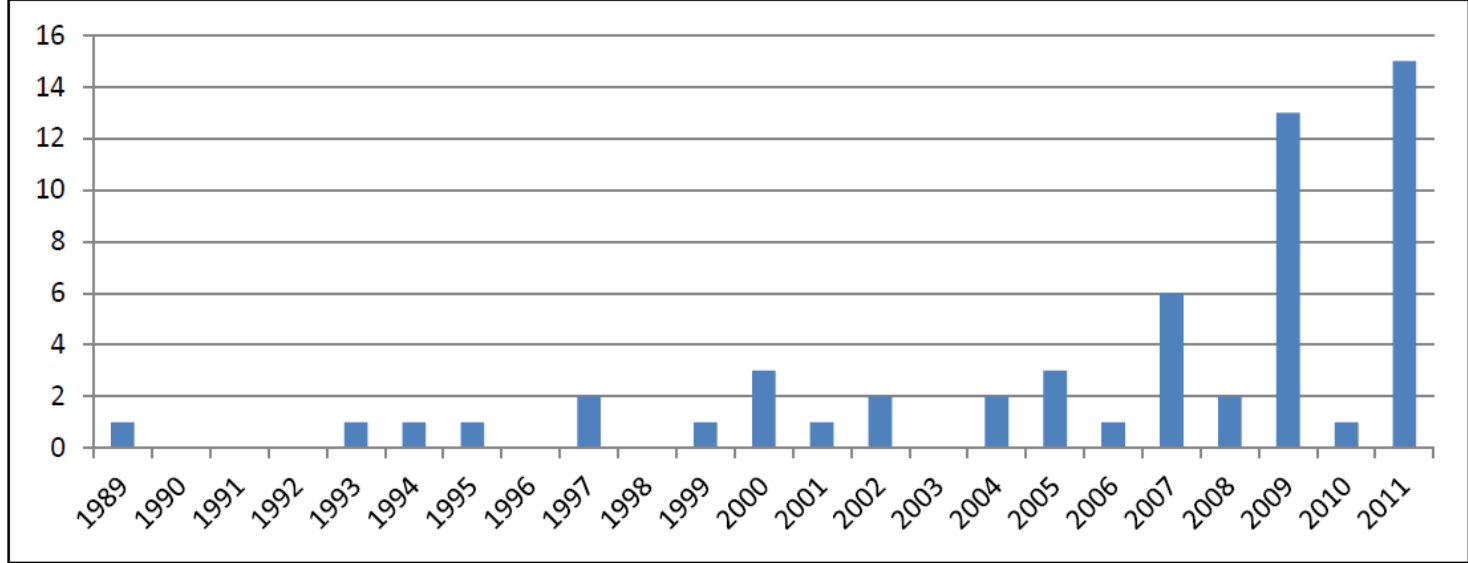

Fonte: HEILMANN, S.; SHIH, L. “The rise of industrial policy in China, 1978-2012”. Op. cit., p. 3.

Pode-se argumentar que, entre as décadas de 1980 e 1990, a PI chinesa esteve fincada entre dois modelos extremos: o modo de administração maoista (estabelecimento de metas, planejamento central, alocação de recursos via empresas públicas) e o estilo japonês (competitividade de empresas privadas, estabelecimento de grandes empresas, primeiro no mercado doméstico, depois em nível global).

Em se tratando do dilema entre planejamento e mercado ou do 'socialismo com características chinesas', na primeira fase da abertura, a China executa um modelo de economia planejada com regulação do mercado como suplemento, isto é, uma estrutura 'top-down', na qual, o governo ajusta o mercado e este guia o empresariado ${ }^{39}$. Grosso modo, é importante ressaltar que, na primeira etapa da reforma, a China adotou um caminho intermediário entre estes dois padrões:

\footnotetext{
${ }^{39}$ PING, L. “China”. Op. cit.
} 


\section{Figura 1. Comparação entre os modelos de industrialização da China maoista, China pós-reforma e Japão}

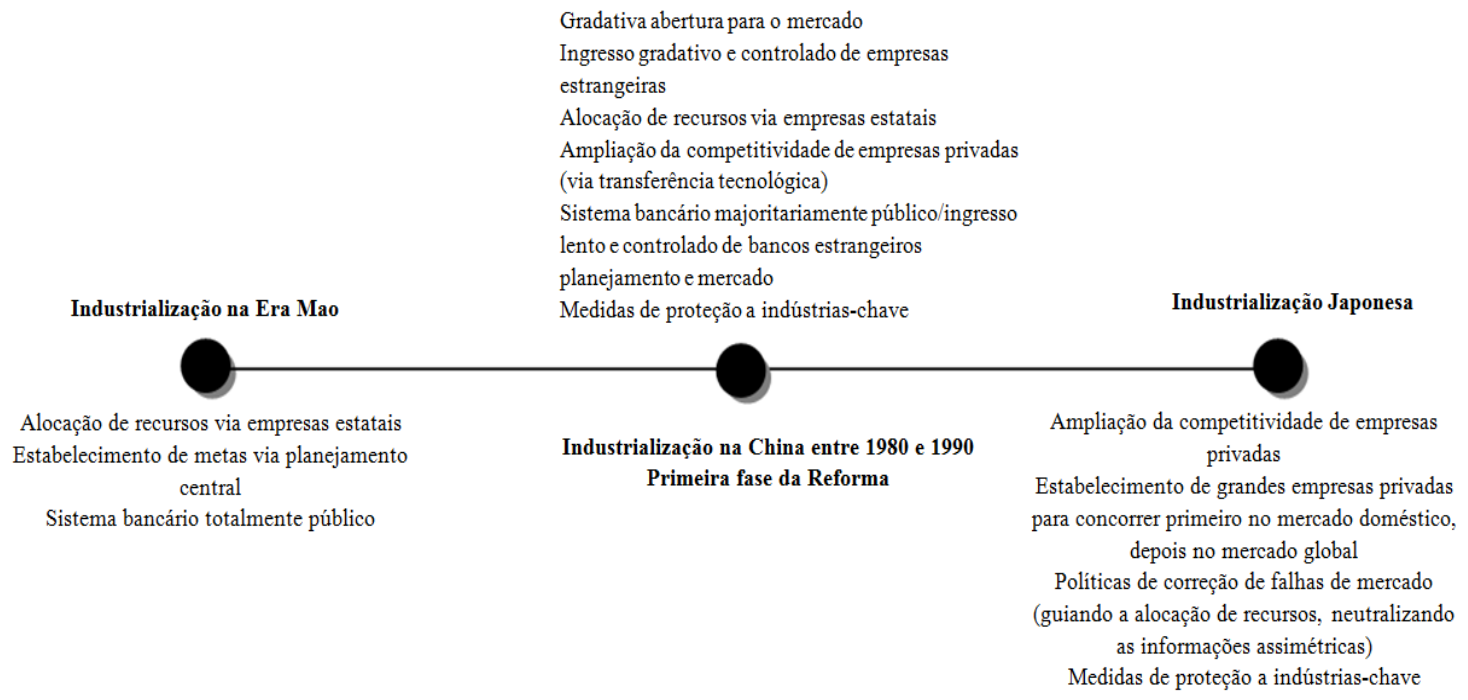

Fonte: Elaboração própria.

Neste esquema são enfatizadas as décadas de 1980 e 1990 por serem consideradas a primeira fase do processo de abertura chinês. Nesta etapa inicial, a reforma ocorre de modo mais vigilante, com importantes restrições ao ingresso de capital estrangeiro, em geral, submetido a reservas geográficas, compelidos a compromissos de transferência tecnológica e à exportação de grande parte da produção.

Diante dos protestos de Tian'anmen, em 1989, devido a insatisfações geradas pelo crescimento do desemprego, aumento da inflação e problemas relacionados à expectativa de uma reforma política, ocorre a partir dos anos 1990, mais especificamente, a partir de 1992, uma reconfiguração da economia chinesa. É deste marco que as restrições ao capital estrangeiro passam a ser afrouxadas e o investimento supera o consumo como variável condutora do gasto agregado, seguido das exportações.

Em meados da década de 1990 se iniciam, também, as preparações para o cumprimento das exigências para ingresso na Organização Mundial do Comércio, que ocorre em 2001, e pode ser considerado um terceiro marco na trajetória chinesa pósreforma. Diante do acesso à $\mathrm{OMC}$, tem-se uma propulsão do movimento de abertura e a China, com uma indústria já robusta, começa a gerar impactos mais relevantes no comércio internacional.

A pauta de exportações da China para o resto do mundo, entre os anos de 1995 e 2014, mostra a dimensão da modificação na estrutura produtiva, essencialmente, a partir 
dos anos 2000. No gráfico abaixo, em azul, é possível verificar a evolução da venda de máquinas e produtos eletrônicos no comércio exterior, estes segmentos passam a ter maior volume e participação nas exportações chinesas:

\section{Gráfico 3. Exportações chinesas entre 1995 e 2014 (em US\$)}

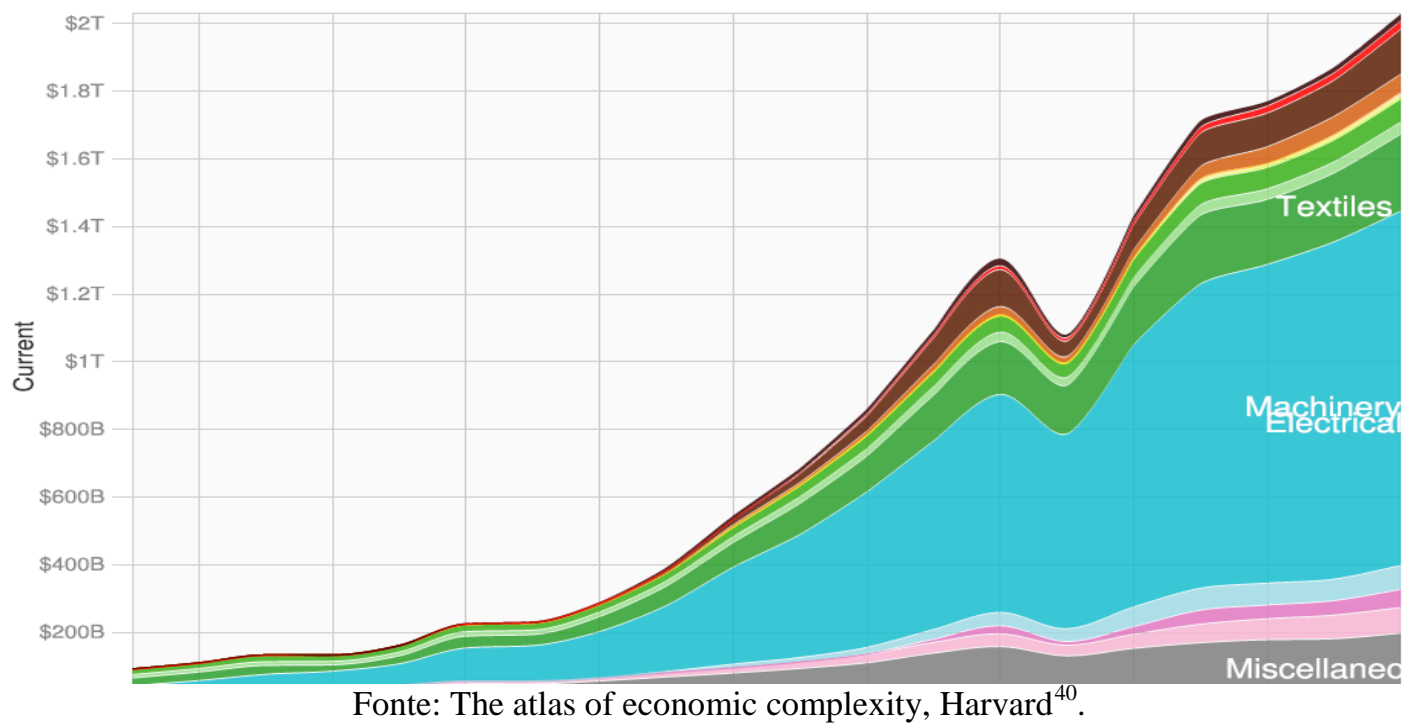

Estes dados são resultado de uma estratégia de industrialização orientada para a exportação, com um papel relevante conferido à inovação. Os gastos em $\mathrm{P} \& \mathrm{D}$ como proporção do PIB na China passaram de 0,71\% em 1990 para 1,52\% em 2008; em 2007, o setor de Pesquisa e Desenvolvimento era responsável por mais de 1,7 milhões de empregos, dos quais mais de $80 \%$ de cientistas e engenheiros. Isto significa algo próximo do total de pesquisadores do Japão, Reino Unido, Alemanha e França juntos. Em termos de número de publicações de engenheiros e cientistas, entre 1995 e 2006, houve um aumento impressionante de 7.980 para $71.184 .{ }^{41}$ Portanto, não se pode tratar do êxito da indústria chinesa e da inserção competitiva da China no comércio internacional sem abordar a estrutura de incentivo ao catching up tecnológico industrial criado a partir do Sistema Nacional de Inovação (SNI).

O fortalecimento do SNI chinês começa em 1985, quando se reconfigura a organização das Academias e dos Institutos de Pesquisa, promovendo reformas que, de forma gradativa, integram o processo de catching up à diversificação industrial. Em 2004, a estratégia voltada para ciência e tecnologia ganha novo impulso, passando a priorizar as transformações necessárias para o desenvolvimento de setores-chave da

\footnotetext{
${ }^{40}$ Disponível em: <http://atlas.cid.harvard.edu/explore/tree_map/import/chn/show/all/2014/>.

${ }^{41}$ LO, D.; WU, M. The State and industrial policy in Chinese economic development. Op. cit.
} 
indústria chinesa. O Sistema Nacional de Inovação chinês torna-se robusto por sua $(i)$ ampla disponibilidade de financiamento, (ii) pela coordenação com a política macroeconômica, (iii) pela harmonização com a política comercial, (iv) pela capacidade de captação de investimento estrangeiro e (v) por seu impacto em termos de ganhos de competitividade da China no comércio internacional ${ }^{42}$.

Deste modo, o SNI chinês é erguido como instrumento central no alcance da fronteira global de inovação, ou seja, é parte fundamental na rápida redução do histórico hiato tecnológico entre a China e os países que assimilaram os avanços desde o século XIX, na Revolução Industrial:

[...] a particularidade da política tecnológica na China não está tanto na fragilidade institucional da economia de mercado, mas deriva do fato de que o sistema nacional de inovação se desenvolve concomitantemente com a expansão do mercado e a criação do tecido empresarial. Igualmente importante, a política tecnológica responde a questionamentos sobre a perda de centralidade da China na economia global e nas posições de fronteira em ciência e tecnologia a partir e meados do século XIX. Pode-se dizer que a modernização científica e tecnológica antecede e, por certos versos, guia a política industrial.$^{43}$

Junto à estruturação de um eficiente Sistema Nacional de Inovação, a prática da política industrial consistiu, ainda, em um processo de aprendizado, principalmente adaptando práticas que levaram o Japão a êxito. Desta forma, foram estabelecidas as seguintes comissões: comissão de planejamento, comissão econômica, comissão de reforma estrutural. A tabela 4 mostra as proposições de cada um desses agentes da política industrial chinesa:

\section{Tabela 4. Estratégia das comissões de política industrial com base no modelo japonês}

\begin{tabular}{|c|c|c|}
\hline & \multirow[b]{2}{*}{$\begin{array}{c}\text { Arcabouço Japonês (pesquisa e proposta } \\
\text { política) }\end{array}$} & \multirow[b]{2}{*}{ Núcleo racional } \\
\hline & & \\
\hline Comissão de Planejamento & $\begin{array}{c}\text { Planejamento setorial para vários anos; apoio para } \\
\text { as indústrias-pilar; promoção de novas indústrias } \\
\text { estratégicas. }\end{array}$ & $\begin{array}{c}\text { Intervenção governamental } \\
\text { (estabelecer um controle-macro) }\end{array}$ \\
\hline Comissão Econômica & $\begin{array}{l}\text { Estabelecimentos de grupos empresariais de larga } \\
\text { escala (semelhantes às keiretsu japonesas); } \\
\text { Fundação de associações empresariais } \\
\text { parcialmente reguladas pelo Estado. }\end{array}$ & $\begin{array}{l}\text { Manter um relacionamento entre } \\
\text { governo e setor privado } \\
\text { (estabelecer um controle-micro) }\end{array}$ \\
\hline $\begin{array}{l}\text { Comissão de Reforma } \\
\text { Estrutural }\end{array}$ & $\begin{array}{l}\text { Separação entre governo e empresas; } \\
\text { estabelecimento de conselhos formados por } \\
\text { governo e setor privado. }\end{array}$ & $\begin{array}{l}\text { Expandir a autonomia das empresas } \\
\text { (inserir mais mecanismos de mercado) }\end{array}$ \\
\hline
\end{tabular}

\footnotetext{
${ }^{42}$ JAGUARIBE, A. "Capacidades estatais comparadas: China e a reforma do Sistema Nacional de Inovação”. In: Texto para discussão, n. 2085. Instituto de Pesquisa Econômica Aplicada. Brasília: IPEA, 2015.

${ }^{43}$ Ibidem, p. 9, grifo nosso.
} 
Fonte: Adaptado de HEILMANN, S.; SHIH, L. “The rise of industrial policy in China, 1978-2012.” Op. cit., p. 7. Elaboração própria.

É possível observar, pelas propostas das comissões, um nítido processo gradativo, onde o Estado se mantém em setores que são tomados como estratégicos (controle-macro); se retira, em certos setores, mantendo canais de acompanhamento (controle-micro), sem deixar de expandir a autonomia do capital privado (inserção de mecanismos de mercado). Nisto se nota a coordenação entre diversos agentes, sendo estabelecidas vias de interação com o setor privado, o qual é parte ativa da política industrial chinesa, como propositor, e passiva, como tomador de contrapartidas exigidas pelo Estado.

Além da coordenação entre os agentes e do aprendizado com as experiências de crescimento no Leste Asiático, a política industrial chinesa obteve êxito em seus resultados, em boa medida, pela noção de continuidade, de etapas a atingir. Conforme argumentam Coelho e Masiero, ${ }^{44}$ a partir das reformas de 1978, teve início um movimento de reorganização da estrutura industrial havendo, após 1989, uma estratégia mais contundente e demarcada de política industrial ativa, que passa a ser, inclusive, assumida institucionalmente, ao serem emitidas diretrizes específicas para a indústria a partir do Sétimo Plano Quinquenal.

Pode-se, então, identificar uma política industrial mais ativa na China a partir dos anos 1990, o que torna seus resultados ainda mais impressionantes. Já no início dos anos 2000, o país ampliava tanto sua participação no comércio internacional quanto a proporção de produtos manufaturados ou, ainda, o grau de sofisticação de sua pauta exportadora. Em 1991, do total exportado, 22\% eram produtos primários; em 2001, portanto, em apenas dez anos, esta participação caiu para 9\%. Os manufaturados eram $77 \%$ da pauta exportadora em 1991, chegaram a 90\% em 2001. Esta estratégia foi parte da dinâmica chinesa fincada na importação de bens de capital, transferência tecnológica, captação de investimento estrangeiro e exportação de máquinas e equipamentos. ${ }^{45}$

\footnotetext{
${ }^{44}$ COELHO, D. B.; MASIERO, G. "A política industrial chinesa como determinante de sua estratégia going global". In: Revista de Economia Política. Vol. 34, nº 1 (134), pp. 139-157, janeiro-marco, 2014. ${ }^{45}$ Ibidem.
} 


\section{Comentários Finais}

O processo de desenvolvimento econômico chinês é um fenômeno que impacta profundamente o direcionamento político-econômico do sistema internacional. Neste breve artigo, procurou-se demonstrar as principais etapas de construção da China que se tem hoje: segunda economia mundial com crescente destaque geopolítico. A intenção foi demonstrar que a China não surge a partir de medidas liberalizantes, mas, de um Estado forte, que vai desde a presença total, como alocador de recursos, até a gradativa inserção de elementos privados e de capital estrangeiro. A política industrial teve papel fundamental na dinâmica econômica chinesa, o que demonstra, de forma nítida, que a superação do subdesenvolvimento passa pela estruturação de uma indústria forte, capaz de competir internacionalmente. Sem Estado, não haveria um desempenho desta magnitude. Portanto, é necessário destacar que o setor privado surge como elemento coadjuvante à eficiência de uma economia planificada, que tem no desenvolvimento um projeto político.

\section{Referências bibliográficas}

CARVALHO, M. H. A evolução econômica e política da China no período maoista (19491978). Disponível em: <http://www.niepmarx.com.br/MM2015/anais2015/mc84/Tc841.pdf〉. Acesso em: 22 mar. 2017.

CHENG, A. História do Pensamento Chinês. Rio de Janeiro: Vozes, 2008.

COELHO, D. B.; MASIERO, G. "A política industrial chinesa como determinante de sua estratégia going global". Revista de Economia Política. Vol. 34, no 1 (134), pp. 139-157, janeiro-marco, 2014.

DIEGUES, A. C.; MILARÉ, L. F. L. "Contribuições da Era Mao Tse-Tung para a industrialização chinesa." Revista Economia Contemporânea, Rio de Janeiro, v. 16, n. 2, p. 359-378 mai-ago/2012.

FAIRBANK, K. J.; GOLDMAN, M. China: a new history. London: The Belknap Press of Harvard University Press, 2006.

FRANK, A. G. ReOrient: global economy in the Asian age. Los Angeles: University of California Press, 1998.

GONÇALVES, A. "China's swing from a planned soviet-type economy to an ingenious socialist market economy: an account of 50 years." Working Papers Series, Social Sciences Research $\quad 2006 . \quad$ Detwork, Disponível em: <http://ssrn.com/abstract=949371> ou<http://dx.doi.org/10.2139/ssrn.949371>. Acesso em: 17 março 2017.

HARVEY, D. O neoliberalismo: histórias e implicações. $3^{\text {a }}$ edição. São Paulo: Edições Loyola, 2012.

Para entender o capital: livro I. São Paulo: Boitempo, 2013.

17 contradições e o fim do capitalismo. $1^{\text {a }}$ edição. São Paulo: Boitempo, 2016.

HEILMANN, S.; SHIH, L. "The rise of industrial policy in China, 1978-2012". HarvardYenching Institute.Working Paper Series, 2013. 
JAGUARIBE, A. Capacidades estatais comparadas: China e a reforma do Sistema Nacional de Inovação. In: Texto para discussão, n. 2085. Instituto de Pesquisa Econômica Aplicada. Brasília: IPEA, 2015.

KENNY, T. Lições da NEP soviética para Economia Socialista de Mercado da China Popular. 2008. Disponível em: <http://www.hist-socialismo.com/docs/NEPsovieticaESMChina.pdf>. Acessoem: 27 Mar. 2017.

KUEH, Y. Y. "Mao and agriculture in China's industrialization: three antitheses in a 50-year perspective." The China Quartely. 2006. Disponível em: <https://www.cambridge.org/core/services/aop-cambridgecore/content/view/S03057410 06000336>. Acesso em: 15 mar. 2017.

LANGE, O. Ensaios sobre planificação econômica. São Paulo: Nova Cultural, 1986.

LYRIO, M. C. A ascensão da China como potência: fundamentos políticos internos. Brasília: FUNAG, 2010.

LO, D.; WU, M. The State and industrial policy in Chinese economic development. Disponível em: <http://www.ilo.org/global/publications/books/WCMS_315676/lang-en/index.htm>. Acesso em: 27 Abril 2017.

MEDEIROS, C. A. "Globalização e a inserção internacional diferenciada da Ásia e América Latina.” In: TAVARES, M. C.; FIORI, J. L. (Orgs.). Poder e dinheiro, uma economia política da globalização. Ed. Vozes, Petrópolis, RJ, 1997.

Notas sobre o desenvolvimento econômico recente na China. São Paulo: Instituto de Estudo Avançados USP, 1998.

"A China como um duplo polo na Economia Mundial e a recentralização asiática."

In: Revista de Economia Política. São Paulo, v. 26, n. 3, p. 381-400, julho/setembro. 2006.

"Estratégias nacionais de desenvolvimento." In: Padrões de desenvolvimento econômico (1950-2008): América Latina, Ásia e Rússia. Brasília: Centro de Gestão e Estudos Estratégicos (CGEE), 2013.

"Padrões de investimento, mudança institucional e transformação estrutural na economia chinesa." Padrões de desenvolvimento econômico (1950-2008): América Latina, Brasília: Ásia e Rússia. Centro de Gestão e Estudos Estratégicos (CGEE), 2013.

NAUGHTON, Barry. The Chinese Economy: transitions and growth. Cambridge, MA: MIT Press, 2007.

PAINE, S. "Spatial Aspects of Chinese Development: issues, outcomes and policies 19491979." The Journal of Development Studies, 1983.

PALESE, A. "The Great Leap Forward (1958-1961): Historical events and causes of one of the biggest tragedies in People's Republic of China's history." Språk-ochlitteraturcentrum, 2009.

PING, L. "China". LASTRES, H. M. M.; SCERRI, M. (orgs.). The role of the State. Nova Deli: Routledge, 2014.

PINGYAO, L. "China's economic growth: new trends and implications." China \& World Economy. N. 1, 2003.

"China's foreign trade: achievements, determinants and future policy challenges."

In: China \& World Economy. 2004, V. 12, N. 6, pp. 38-50.

POMAR, W. A Revolução Chinesa. São Paulo: Editora Unesp, 2003.

O enigma chinês. $2^{a}$ Edição. São Paulo: Fundação Perseu Abramo, 2015.

RUIZ, R. M. Polarizações e desigualdades: desenvolvimento regional na China. Texto para Discussão. Belo Horizonte: UFMG/Cedeplar, n. 299, 2006. 